Article

\title{
Lower-Limb Lymphedema after Sentinel Lymph Node Biopsy in Cervical Cancer Patients
}

\author{
David Cibula 1,*,+(D), Martina Borčinová ${ }^{1, \dagger}$, Simone Marnitz ${ }^{2}$, Jiří Jarkovský ${ }^{3}$, Jaroslav Klát ${ }^{4, \dagger}$, Radovan Pilka ${ }^{5,+}$, \\ Aureli Torné ${ }^{6}\left(\mathbb{D}\right.$, Ignacio Zapardiel ${ }^{7} \mathbb{D}$, Almerinda Petiz ${ }^{8}$, Laura Lay ${ }^{9}$, Borek Sehnal ${ }^{10},+{ }^{\text {, Jordi Ponce }}{ }^{11} \mathbb{D}$, \\ Michal Felsinger ${ }^{12,+}$, Octavio Arencibia-Sánchez ${ }^{13}$, Peter Kaščák ${ }^{14,+}{ }^{+}$, Kamil Zalewski ${ }^{15,+}{ }^{+}$Jiri Presl ${ }^{16,+}$, \\ Alicia Palop-Moscardó ${ }^{17}$ (D), Solveig Tingulstad ${ }^{18}$, Ignace Vergote ${ }^{19, \ddagger}$, Mikuláš Redecha ${ }^{20,+}$, Filip Frühauf ${ }^{1,+}$, \\ Christhardt Köhler ${ }^{2}$ and Roman Kocián ${ }^{1,+}$
}

check for updates

Citation: Cibula, D.; Borčinová, M.; Marnitz, S.; Jarkovský, J.; Klát, J.; Pilka, R.; Torné, A.; Zapardiel, I.;

Petiz, A.; Lay, L.; et al. Lower-Limb Lymphedema after Sentinel Lymph Node Biopsy in Cervical Cancer Patients. Cancers 2021, 13, 2360. https://doi.org/10.3390/ cancers 13102360

Academic Editor: David Wong

Received: 6 April 2021

Accepted: 11 May 2021

Published: 13 May 2021

Publisher's Note: MDPI stays neutral with regard to jurisdictional claims in published maps and institutional affiliations.

Copyright: (c) 2021 by the authors. Licensee MDPI, Basel, Switzerland. This article is an open access article distributed under the terms and conditions of the Creative Commons Attribution (CC BY) license (https:/ / creativecommons.org/licenses/by/ $4.0 /)$.
1 Gynecologic Oncology Center, Department of Obstetrics and Gynecology, First Faculty of Medicine, Charles University and General University Hospital, 12000 Prague, Czech Republic; martina.borcinova@vfn.cz (M.B.); filip.fruehauf@vfn.cz (F.F.); roman.kocian@vfn.cz (R.K.)

2 Department of Special Operative and Oncologic Gynaecology, Asklepios-Clinic Hamburg, 22763 Hamburg, Germany; simone.marnitz-schulze@uk-koeln.de (S.M.); ch.koehler@asklepios.com (C.K.)

3 Data Analysis Department, Institute of Biostatistics and Analyses, Faculty of Medicine, Masaryk University, 62500 Brno, Czech Republic; jarkovsky@iba.muni.cz

4 Department of Obstetrics and Gynecology, University Hospital Ostrava, 70800 Ostrava Poruba, Czech Republic; jaroslav.klat@fno.cz

5 Department of Obstetrics and Gynecology, Faculty of Medicine and Dentistry, Palacky University, University Hospital Olomouc, 77900 Olomouc, Czech Republic; radovan.pilka@fnol.cz

6 Unit of Gynecological Oncology, Institute Clinic of Gynaecology, Obstetrics, and Neonatology, Hospital Clinic-Institut d'Investigacions Biomediques August Pi i Sunyer (IDIBAPS), University of Barcelona, 08036 Barcelona, Spain; atorne@clinic.cat

7 Gynecologic Oncology Unit, La Paz University Hospital, 28046 Madrid, Spain; ignacio.zapardiel@uam.es

8 Serviço de Ginecologia, Instituto Portugues de Oncologia do Porto, 1099-023 Porto, Portugal; almerindapetiz@ipoporto.min-saude.pt

9 Department of Gynaecology, Institute of Oncology Angel H Roffo University of Bueno s Aires, Buenos Aires C1417 DTB, Argentina; consultas@dralauralay.com

10 Department of Obstetrics and Gynecology, First Faculty of Medicine, University Hospital Bulovka, Charles University, 18081 Prague, Czech Republic; borek.sehnal@bulovka.cz

11 Department of Gynecology, Biomedical Research Institute of Bellvitge (IDIBELL), University Hospital of Bellvitge, University of Barcelona, 08908 Barcelona, Spain; jponce@bellvitgehospital.cat

12 Department of Gynecology and Obstetrics, Faculty of Medicine, Masaryk University, 60177 Brno, Czech Republic; felsinger.michal@fnbrno.cz

13 Departments of Gynecologic Oncology, University Hospital of the Canary Islands, 35016 Las Palmas de Gran Canaria, Spain; oaresan@gobiernodecanarias.org

14 Department of Obstetrics and Gynecology, Faculty Hospital Trencin, 91171 Trencin, Slovakia; Peter.kascak@fntn.sk

15 Department of Gynecologic Oncology, Holycross Cancer Center, 25-734 Kielce, Poland; SCOinfo@onkol.kielce.pl

16 Department of Obstetrics and Gynecology, Faculty of Medicine Pilsen, University Hospital in Pilsen and Charles University, 30460 Pilsen, Czech Republic; preslj@fnplzen.cz

17 Gynecology Department, Instituto Valenciano de Oncologia (IVO), 46009 Valencia, Spain; apalop@fivo.org

18 Department of Obstetrics and Gynecology, Trondheim University Hospital, 7030 Trondheim, Norway; Solveig.Tingulstad@stolav.no

19 Department of Gynecology and Obstetrics, Leuven Cancer Institute, University Hospital Leuven, 3000 Leuven, Belgium; ignace.vergote@uzleuven.be

20 Department of Gynaecology and Obstetrics, University Hospital, Comenius University, 81499 Bratislava, Slovakia; redecha2@uniba.sk

* Correspondence: dc@davidcibula.cz; Tel.: +420-224-967-451

+ Central and Eastern European Gynecologic Oncology Group, CEEGOG.

$\ddagger$ Belgium and Luxembourg Gynaecological Oncology Group, BGOG.

Simple Summary: Lower-limb lymphedema (LLL) is a well-recognized adverse outcome of the surgical management of cervical cancer. Recently, sentinel lymph node (SLN) biopsy has emerged as an alternative procedure to systematic pelvic lymphadenectomy (PLND) aiming to decrease the risk of complications, especially LLL development. Our study represents the first prospective 
analysis of LLL incidence in cervical cancer patients after a uterine procedure with SLN biopsy, without systematic PLND. In an international multicenter trial SENTIX, the group of 150 patients was prospectively evaluated using both objective and subjective LLL assessments in 6 months intervals for 2 years. Contrary to the expectations, our results showed that SLN biopsy does not eliminate the risk of LLL development which occurred in a mild or moderate stage in about $26 \%$ of patients with a median interval to the onset of 9 months.

Abstract: Background: To prospectively assess LLL incidence among cervical cancer patients treated by uterine surgery complemented by SLN biopsy, without PLND. Methods: A prospective study in 150 patients with stage IA1-IB2 cervical cancer treated by uterine surgery with bilateral SLN biopsy. Objective LLL assessments, based on limb volume increase (LVI) between pre- and postoperative measurements, and subjective patient-perceived swelling were conducted in six-month periods over 24-months post-surgery. Results: The cumulative incidence of LLL at 24 months was $17.3 \%$ for mild LLL (LVI 10-19\%), 9.2\% for moderate LLL (LVI 20-39\%), while only one patient (0.7\%) developed severe LLL (LVI > 40\%). The median interval to LLL onset was nine months. Transient edema resolving without intervention within six months was reported in an additional $22 \%$ of patients. Subjective LLL was reported by $10.7 \%$ of patients, though only a weak and partial correlation between subjective-report and objective-LVI was found. No risk factor directly related to LLL development was identified. Conclusions: The replacement of standard PLND by bilateral SLN biopsy in the surgical treatment of cervical cancer does not eliminate the risk of mild to moderate LLL, which develops irrespective of the number of SLN removed.

Keywords: cervical cancer; sentinel lymph node biopsy; lower limb lymphedema; pelvic lymphadenectomy

\section{Introduction}

Lower limb lymphedema (LLL) ranks amongst the most serious types of enduring postoperative morbidity following surgical lymph node staging in gynecological cancer patients [1]. It represents a manifestation of lymphatic system insufficiency and deranged lymph transport [2] and is characterized by swelling of one or both lower limbs caused by excess accumulation of water, plasma proteins, extravascular blood cells, and parenchymal/stromal cell products [3]. LLL significantly decreases the quality of life of gynecological cancer survivors, negatively affecting daily life activities as well as their social and sexual life [4]. Since the worldwide median age of cervical cancer diagnosis is mid-to-late 40 s, with $25 \%$ diagnosed under the age of 40 , minimizing the long-term risk of LLL in this relatively young population with an excellent prognosis in early stages is of particular importance $[5,6]$.

The true incidence of LLL after surgical treatment of cervical cancer is unclear, previously reported in the range of $0-62 \%$ [7-15]. The incidence varies mainly according to the extent of the surgery and administration of adjuvant treatment [16-19]. Namely, the number of removed lymph nodes has been shown to be directly related to the LLL development; however, the critical number of lymph nodes varied from 10 to 31 [9,15,20-23].

The main motive for introducing sentinel lymph node (SLN) biopsy as a replacement of standard systematic pelvic lymphadenectomy (PLND) is to decrease postoperative morbidity, specifically the development of LLL. Since the average number of SLN among cervical cancer patients is between $2-4$ and removal of SLN does not usually require a complete dissection of pelvic spaces and interruption of all main lymphatic trunks, substantial reduction of LLL is expected after SLN biopsy without systematic PLND [24-26]. Implementation of SLN biopsy was already shown to be an effective strategy in reducing the incidence of LLL after treatment of endometrial or vulvar cancer [27-30]. On the other hand, only a few studies reported the incidence of LLL in cervical cancer patients after SLN biopsy 
without simultaneous PLND, mostly being retrospective and with substantial flaws in the methodology of LLL assessment [25,26,31].

The aim of the present study was to perform a pre-planned analysis of the incidence of LLL in a cohort of 150 patients who reached at least 24 months follow-up in a prospective international multicenter cohort study, SENTIX.

\section{Materials and Methods}

\subsection{Study Design and Participants}

In this pre-planned interim analysis, data were analyzed from 150 patients who were treated per protocol in the SENTIX trial and had two years of follow-up data available. Patients were enrolled in the study between 05/2016 and 11/2017.

SENTIX (SENTinel lymph node in cervIX cancer) is a prospective, multicenter, observational trial on SLN biopsy in patients with early-stage cervical cancer, with the primary endpoint being the recurrence rate at the 24th month of follow-up. The pre-planned secondary endpoint was the assessment of the prevalence of LLL. Cervical cancer patients with FIGO 2009 [32] stage IA1 with lymphovascular space invasion, IA2, or IB1, who lacked suspicious lymph nodes on preoperative imaging, had a common histological tumor type (squamous, adeno- or adenosquamous carcinoma), and the largest tumor diameter less than $4 \mathrm{~cm}$ (less than $2 \mathrm{~cm}$ for patients scheduled for a fertility-sparing procedure), were pre-registered into the study. All pre-registered patients underwent radical hysterectomy or a fertility-sparing procedure with sentinel lymph node dissection, without PLND. After the surgery, patients were registered if they met additional intraoperative criteria: bilateral SLN detection, no metastasis of any size found on frozen sections, and no evidence of more advanced disease (Figure 1). All retrieved sentinel lymph nodes were consequently processed by ultrastaging protocol, as described elsewhere [24].

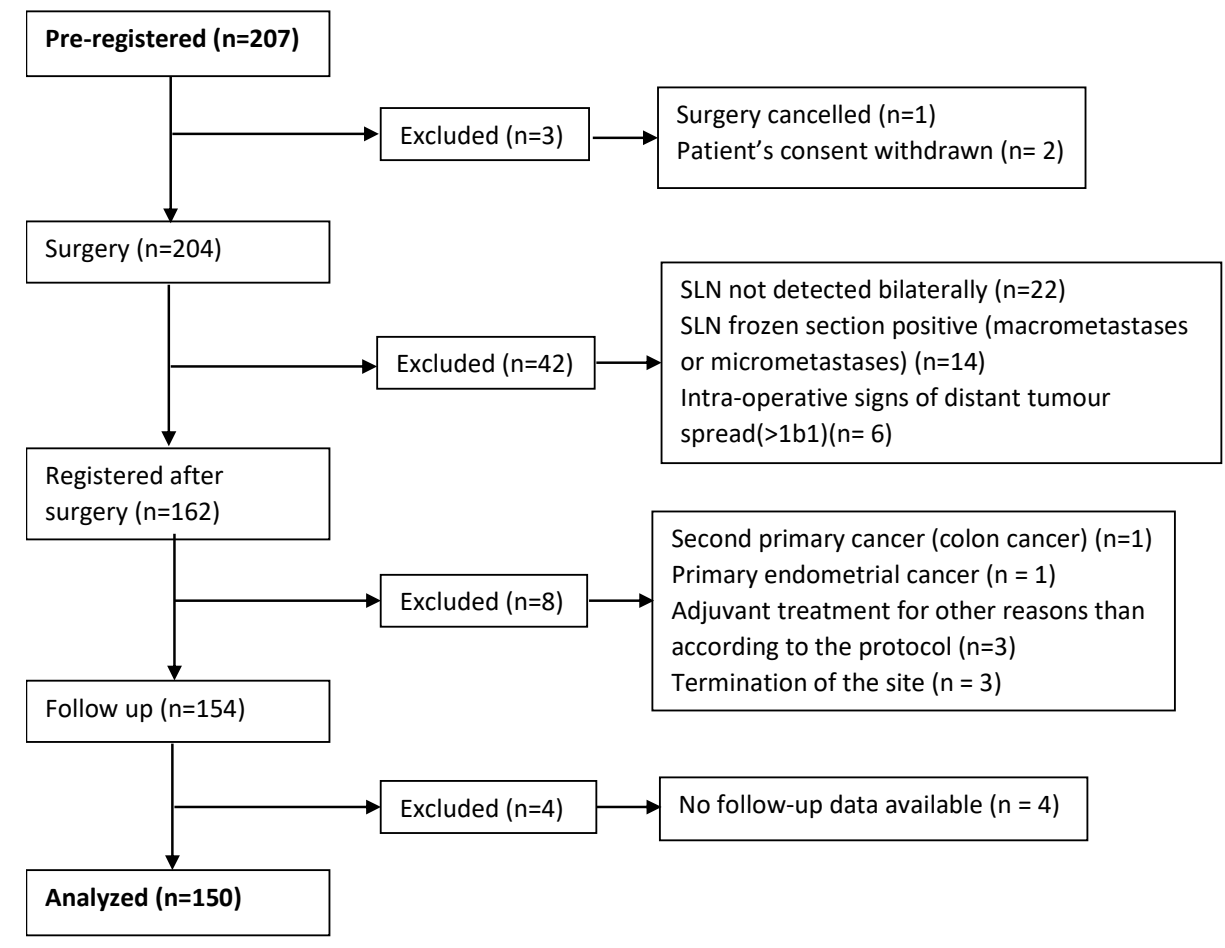

Figure 1. Flow chart of patients registered in the SENTIX trial.

\subsection{Objective Secondary LLL Assessment}

Limb volume assessment was performed at the preoperative visit and subsequently during follow-up visits, every six months for two years after surgery. Each limb was measured at five standardized levels ( $\mathrm{C} 1-\mathrm{C} 5)$ : $\mathrm{C} 1-10 \mathrm{~cm}$ below anterior superior iliac spine; $\mathrm{C} 2-10 \mathrm{~cm}$ above the midpoint of the knee joint; $\mathrm{C} 3-10 \mathrm{~cm}$ below the midpoint of 
the knee joint; C4-10 cm above the medial ankle (malleolus); C5-level of the medial ankle (malleolus) (Figure S1). All measurements were performed under standardized conditions: (i) a flexible tape measure was used; (ii) the patient was lying still in a supine, relaxed position with the leg straight; (iii) markings were applied on the skin in five defined levels; and (iv) the tape was kept at right angles to the limb length axis in all girth measurements.

The total limb volume was calculated as a sum of the volumes of four individual segments (Equation (1)). The volume of each limb segment was calculated based on the truncated cone formula, where $h=$ height of the segment, $A=$ circumference at the top of the segment, $B=$ circumference at the bottom of the segment.

$$
V_{\text {limb }}=\sum \frac{(h) *\left(A^{2}+A * B+B^{2}\right)}{12 * \pi}
$$

Above-knee volume (thigh volume) was calculated as a volume of the segment between the C1 and C2 levels. The below-knee volume (calf and ankle volume) was calculated as a sum of segments C3-C4 and C4-C5.

Lymphedema was classified at 24-months follow-up as a persistent limb volume increase (LVI) of 10-19\% (mild LLL), 20-39\% (moderate LLL), and $>40 \%$ (severe LLL) between preoperative and postoperative assessments [33,34]. Chosen threshold of $10 \%$ LVI was based on a prior paper of Spillane et al. [35] who correlated volume thresholds with patient-reported outcomes $>7 \%$ increase in the sum of circumferential measurements provided a robust definition of LLL with a sensitivity of $50 \%$ and specificity of $100 \% .>7 \%$ increase in the sum of circumferential measurements equals $10-12 \%$ of LVI.

Persistent LVI was characterized as a volume change persisting over the period of at least six months, i.e., observed at least during the two consequent follow-up visits.

\subsection{Patient-Reported LLL}

At each follow-up visit, all patients were inquired using an unvalidated questionnaire for their subjective assessment of each lower leg swelling during the past six months, separately for five levels: loin, thigh, calf, ankle, and foot. Should the patient report swelling in either of the levels at least at two follow-up visits, the subjective assessment was considered positive.

\subsection{Statistics}

Standard descriptive statistics were applied in the analysis: absolute and relative frequencies for categorical variables and median supplemented by 5th-95th percentile range for continuous variables. The statistical significance of the relationship between the objective and subjective evaluation of lymphedema was tested using Fisher's exact test and the Pearson correlation coefficient for binary data and its statistical significance. The predictive power of patient characteristics for lymphedema endpoint occurrence was analyzed using logistic regression and described by odds ratios and their $95 \%$ confidence interval and statistical significance. Kaplan-Meier methodology was adopted for the description of time to lymphedema development. $\alpha=0.05$ was adopted as a level of statistical significance in all analyses. The analysis was computed using SPSS 25.0.0.1 (IBM Corporation, 2019) and R with package ggplot2.

\subsection{Study Approval}

The protocol was approved by the Institutional Review board of the leading institution (General University Hospital in Prague, Prague, Czech Republic) in 2015. Institutional review board approval of all participating sites was a prerequisite for participation. All participating patients signed informed consent before enrolling in the study. The study was performed in accordance with the Declaration of Helsinki. SENTIX is conducted as a European Network of Gynecological Oncology Trial Groups (ENGOT) trial (ENGOT Cx2) and is led by the Central and Eastern European Gynecologic Oncology Group (CEEGOG; CEEGOG Cx1). The study is performed according to ENGOT Model A [36]. 


\section{Results}

\subsection{Patient Characteristics}

We analyzed the data from 150 patients treated per protocol and followed for at least 24 months in a prospective international multicentric trial on SLN biopsy in cervical cancer (SENTIX). The characteristics of the patients are summarized in Table 1. The majority of patients had pre-treatment FIGO stage IB1 (128 patients/85.3\%), preoperative tumor size $\leq 2 \mathrm{~cm}(107 / 71.3 \%)$, and squamous cell tumor histotype $(102 / 68.0 \%)$. The median number of removed SLNs per patient was three (5th-95th percentile: $2-6.55)$. The most common localization of SLN was the interiliac region (46.7\%), followed by the external iliac region $(42.5 \%)$ and the common iliac region (10.2\%). Only two of all removed SLNs were localized in the presacral region.

Table 1. Characteristics of patients $(n=150)$.

\begin{tabular}{|c|c|c|}
\hline Parameter & Category & $n(\%)$ \\
\hline \multirow{3}{*}{ Age category (years) } & $\leq 40$ & $54(36.0 \%)$ \\
\hline & $41-60$ & $78(52.0 \%)$ \\
\hline & $>60$ & $18(12.0 \%)$ \\
\hline \multirow{3}{*}{$\begin{array}{l}\text { Body mass index category } \\
\qquad\left(\mathrm{kg} / \mathrm{mg}^{2}\right)\end{array}$} & $\leq 25$ & $79(52.7 \%)$ \\
\hline & $26-30$ & $41(27.3 \%)$ \\
\hline & $>30$ & $30(20.0 \%)$ \\
\hline \multirow{2}{*}{ ECOG performance status } & 0 & $146(97.3 \%)$ \\
\hline & 1 & $4(2.7 \%)$ \\
\hline \multirow{3}{*}{ FIGO stage (preoperative) } & IA1 + LVSI & $10(6.7 \%)$ \\
\hline & IA2 & $12(8.0 \%)$ \\
\hline & IB1 & $128(85.3 \%)$ \\
\hline \multirow{3}{*}{ Grade } & G1 & $32(21.3 \%)$ \\
\hline & G2 & $85(56.7 \%)$ \\
\hline & G3 & $33(22.0 \%)$ \\
\hline \multirow{3}{*}{ Tumor type } & Squamous cell carcinoma & $102(68.0 \%)$ \\
\hline & Adenocarcinoma & $46(30.7 \%)$ \\
\hline & Adenosquamous carcinoma & $2(1.3 \%)$ \\
\hline \multirow{2}{*}{$\begin{array}{c}\text { Tumor size (preoperative } \\
\text { imaging) }\end{array}$} & $\leq 2 \mathrm{~cm}$ & $107(71.3 \%)$ \\
\hline & $>2 \mathrm{~cm}$ & $43(28.7 \%)$ \\
\hline \multirow{2}{*}{$\begin{array}{l}\text { Lymphovascular space invasion } \\
\text { (LVSI) }\end{array}$} & Yes & $40(26.7 \%)$ \\
\hline & No & $110(73.3 \%)$ \\
\hline \multirow{2}{*}{ Surgical approach } & Laparotomy & $50(33.3 \%)$ \\
\hline & Minimally invasive & $100(66.7 \%)$ \\
\hline \multirow{5}{*}{ Type of uterine procedure } & Type B radical hysterectomy & $36(24.0 \%)$ \\
\hline & Type C1 radical hysterectomy & $61(40.7 \%)$ \\
\hline & Type C2 radical hysterectomy & $24(16.0 \%)$ \\
\hline & Simple hysterectomy & $1(0.7 \%)$ \\
\hline & $\begin{array}{l}\text { FST (conization, } \\
\text { trachelectomy) }\end{array}$ & $28(18.6 \%)$ \\
\hline \multirow{3}{*}{ No of removed SLNs } & 2 & $59(39.3 \%)$ \\
\hline & $3-4$ & $69(46.0 \%)$ \\
\hline & $>4$ & $22(14.9 \%)$ \\
\hline \multirow{3}{*}{ SLN metastatic involvement } & No & $137(91.3 \%)$ \\
\hline & $\begin{array}{l}\text { Macrometastasis or } \\
\text { micrometastasis }\end{array}$ & $9(6.0 \%)$ \\
\hline & Isolated tumor cells & $4(2.7 \%)$ \\
\hline
\end{tabular}


Table 1. Cont.

\begin{tabular}{ccc}
\hline Parameter & Category & $\boldsymbol{n}(\boldsymbol{\%})$ \\
\hline \multirow{3}{*}{ Adjuvant treatment } & Chemoradiotherapy & $12(8.0 \%)$ \\
& Combined radiotherapy & $5(3.3 \%)$ \\
& Brachytherapy & $1(0.7 \%)$ \\
& None & $132(88.0 \%)$ \\
\hline \multirow{2}{*}{ Pregnancy } & No & $144(96.0 \%)$ \\
& Yes & $6(4.0 \%)$ \\
\hline \multirow{2}{*}{ Recurrence } & No & $136(90.7 \%)$ \\
& Yes & $14(9.3 \%)$ \\
\hline \multirow{2}{*}{ Death of disease } & No & $147(98.0 \%)$ \\
& Yes & $3(2.0 \%)$ \\
\hline
\end{tabular}

BMI: body mass index; ECOG: Eastern Cooperative Oncology Group; FST: fertility-sparing treatment; LVSI: lymphovascular space invasion; SLN: sentinel lymph node.

Using ultrastaging protocol [37], nine patients (6\%) were diagnosed with SLN metastasis and treated with adjuvant treatment (eight chemoradiotherapy; one combined radiotherapy). In four patients, isolated tumor cells were detected, though no adjuvant treatment was administered. Adjuvant treatment was administered to six additional patients with positive vaginal margins (two chemoradiotherapy, three combined radiotherapy, one brachytherapy) and three with parametrial tumor involvement (two chemoradiotherapy, one combined radiotherapy). Six out of twenty-eight patients after a fertility-sparing procedure conceived during the follow-up period. Fourteen patients experienced recurrence; three of these died of the disease (Table 1).

\subsection{Objective Assessment of $L L L$}

The incidence of LLL, classified according to persistent limb volume increase (LVI) as mild (LVI 10-19\%), moderate (LVI 20-39\%), or severe (LVI > 40\% LLL), is shown in Figure 2. Individual LVI changes in detail are shown in Figure S2. Overall, 24 patients (cumulative incidence $17.3 \%$ ) experienced persistent mild LLL, 13 patients $(9.2 \%)$ moderate, and one patient $(0.7 \%)$ severe LLL. In the moderate and severe LLL groups, $9 / 14$ patients had bilateral LLL and 5/14 had LLL localized unilaterally, all in the right limb. All patients with unilateral moderate LLL experienced mild LLL in the second extremity. In patients with LLL, two received adjuvant radiotherapy. In one case, the onset of LLL coincided with pregnancy, and in one patient, limb swelling coincided with leg thrombosis (Table S1). Three of the LLL patients experienced recurrence during the 24 months of the follow-up; time of the recurrence in neither case corresponded to LLL development.

The median interval to LLL onset was nine months (95\% CI: 7.0-11.0): 50\% occurred during the first six months, $15.8 \%$ between $6-12$ months, $26.3 \%$ between $12-18$ months, and $7.9 \%$ between $18-24$ months after surgery (Figure 1 ). We did not report any significant tendency for more frequent or earlier swelling in either pre-defined part of the limb (bellow knee vs. above knee) (Figure S3).

Transient edema resolving without intervention during the six-month period was observed in $22 \%$ of patients (either unilaterally or bilaterally) (Figure S4). 


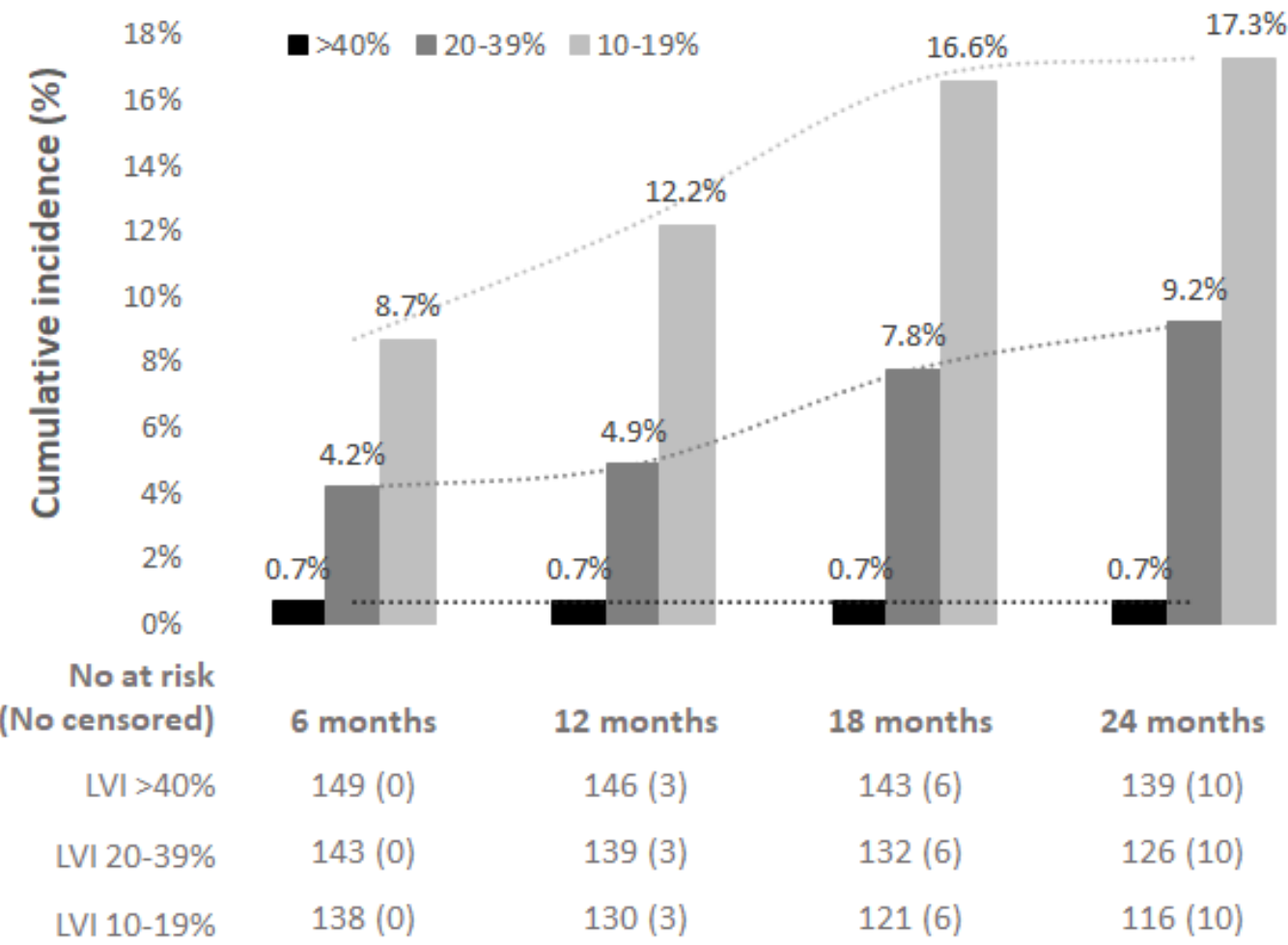

Figure 2. Cumulative incidence of lower-limb lymphedema (LLL) during 24 months of postoperative follow-up. Black: severe LLL (LVI > 40\%); dark grey: moderate LLL (LVI 20-39\%); light grey: mild LLL (LVI 10-19\%). LVI: limb volume increase.

\subsection{Subjective Assessment of LLL}

Only 16 patients $(10.7 \%)$ subjectively reported LLL; eight patients in both limbs and five and three unilaterally in their right and left limb, respectively. In $50 \%$ of patients reporting LLL (8/16), persistent LVI was not objectively observed, frequently reaching negative limb volume change values (Figure 3 ). Only $16.7 \%$ and $23.1 \%$ of patients with mild and moderate objectively assessed LLL reported LLL subjectively (Table S1). Interestingly, the only patient with objective severe LLL reported subjective LLL only for the right limb even though the LVI was comparable (LVI > 60\%) for both limbs (patient 1, Figure S2).
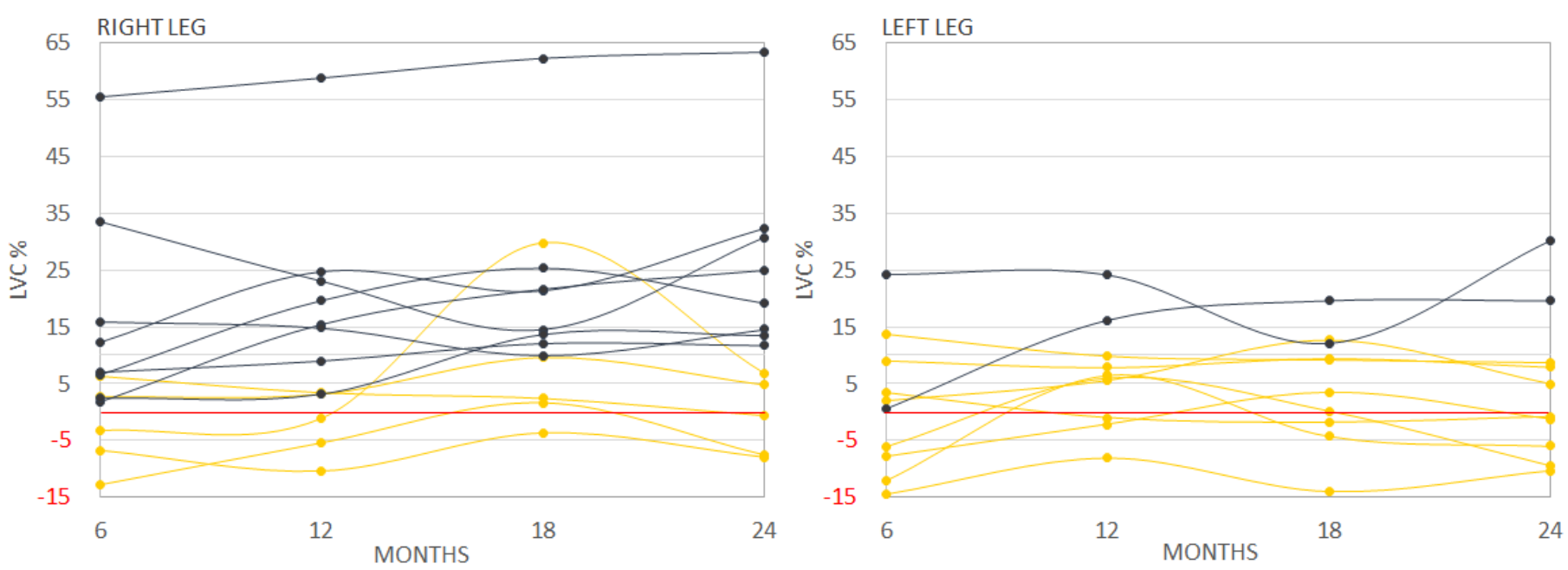

Figure 3. Individual fluctuations of objectively assessed LVC in patients subjectively reporting LLL. Yellow lines: patients without objective LLL; Black lines: patients with objective LLL (all grades). LVC: limb volume change; LVI: limb volume increase. 
Only a weak correlation between the subjectively reported and objectively assessed presence of LLL was found, though only for the right limb. This correlation did not remain positive for the mild LLL subgroup, only being observed in moderate and mild + moderate groups (Table 2).

Table 2. Correlation between subjective and objective LLL assessment.

\begin{tabular}{|c|c|c|c|c|c|c|c|c|}
\hline \multicolumn{9}{|c|}{ Right Limb } \\
\hline & & \multicolumn{2}{|c|}{ Subjective } & \multirow{2}{*}{ Total } & \multirow{2}{*}{$\%$ Sub. } & \multirow{2}{*}{$\begin{array}{c}p \text {-Value } \\
\text { (Fisher Test) }\end{array}$} & \multirow{2}{*}{$\begin{array}{c}\text { Pearson } \\
\text { Correlation }\end{array}$} & \multirow{2}{*}{$p$-Value } \\
\hline & & No & Yes & & & & & \\
\hline \multirow[t]{2}{*}{$\mathrm{LVI}>20 \%$} & no & 127 & 9 & 136 & $6.6 \%$ & & & \\
\hline & yes & 10 & 4 & 14 & $28.6 \%$ & 0.021 & 0.227 & 0.005 \\
\hline \multirow[t]{2}{*}{ LVI 10-19\% } & no & 120 & 9 & 129 & $7.0 \%$ & & & \\
\hline & yes & 17 & 4 & 21 & $19.0 \%$ & 0.087 & 0.149 & 0.069 \\
\hline \multirow[t]{2}{*}{$\mathrm{LVI}>10 \%$} & no & 110 & 5 & 115 & $4.3 \%$ & & & \\
\hline & yes & 27 & 8 & 35 & $22.9 \%$ & 0.002 & 0.278 & 0.001 \\
\hline \multicolumn{9}{|c|}{ Left Limb } \\
\hline & & \multicolumn{2}{|c|}{ Subjective } & & & $p$-Value & Pearson & \\
\hline & & No & Yes & Total & \% Sub. & (Fisher Test) & Correlation & $p$-Value \\
\hline \multirow[t]{2}{*}{ LVI > 20\% } & no & 131 & 10 & 141 & $7.1 \%$ & & & \\
\hline & yes & 8 & 1 & 9 & $11.1 \%$ & 0.506 & 0.037 & 0.656 \\
\hline \multirow[t]{2}{*}{ LVI 10-19\% } & no & 120 & 9 & 129 & $7.0 \%$ & & & \\
\hline & yes & 19 & 2 & 21 & $9.5 \%$ & 0.653 & 0.034 & 0.680 \\
\hline \multirow[t]{2}{*}{$\mathrm{LVI}>10 \%$} & no & 112 & 8 & 120 & $6.7 \%$ & & & \\
\hline & yes & 27 & 3 & 30 & $10.0 \%$ & 0.460 & 0.051 & 0.534 \\
\hline
\end{tabular}

LVI: limb volume increase; sub.: subjective; subjective: subjective assessment. Statistical significance level $p \leq 0.05$.

\subsection{Factors Predisposing to $L L L$}

Logistic regression was employed to ascertain the significance of the inherent prognostic variables (age, BMI, surgical approach, FIGO stage, side-specific number of removed SLNs, radicality of the surgery, adjuvant treatment, tumour size, tumour histotype, grade, LVSI) on the development of objectively assessed LLL. Only an open surgical approach was a marginally significant protective factor for the development of below-knee lymphedema on either limb, with hazard ratio [HR]: 0.255; confidence interval [CI] 0.069, 0.942, $p=0.04$ (right leg); and HR 0.27, CI 0.073, 1.0, $p=0.05$ (left leg) (most relevant tested parameters are summarized in Table 3; full data can be found in Table S2). Neither BMI, number of removed SLNs, or administration of adjuvant therapy were significant. 
Table 3. Risk factors analysis associated with objective LLL at 24 months follow-up.

\begin{tabular}{|c|c|c|c|c|c|c|c|c|c|c|c|c|}
\hline & \multicolumn{2}{|c|}{$\begin{array}{l}\text { Age Categories } \\
\text { (Reference } \leq 40)\end{array}$} & \multicolumn{2}{|c|}{$\begin{array}{l}\text { BMI Categories } \\
\text { (Reference } \leq 25)\end{array}$} & \multicolumn{2}{|c|}{$\begin{array}{l}\text { Surgical Approach } \\
\text { (Reference MIS) }\end{array}$} & \multirow{2}{*}{$\begin{array}{c}\begin{array}{c}\text { FIGO Stage } \\
\text { (Reference IA2 } \\
+ \text { IA1 + LVSI) }\end{array} \\
\text { IB2 } \\
\end{array}$} & \multirow{2}{*}{$\begin{array}{c}\text { No SLN } \\
\text { (Reference } \leq 2)\end{array}$} & \multicolumn{3}{|c|}{$\begin{array}{l}\text { Radical Parametrectomy } \\
\text { (Reference B) }\end{array}$} & \multirow{2}{*}{$\begin{array}{c}\begin{array}{c}\text { Adjuvant } \\
\text { Radiotherapy }\end{array} \\
\text { (Reference No) } \\
\text { Yes }\end{array}$} \\
\hline & $41-60$ & $>60$ & $26-30$ & $>30$ & & arotomy & & & $\mathrm{C} 1$ & $\mathrm{C} 2$ & Not done & \\
\hline $\begin{array}{c}\text { LVI } \\
\text { Localization }\end{array}$ & $p$ & $p$ & $p$ & $p$ & $p$ & OR $(95 \%$ CI) & $p$ & $p$ & $p$ & $p$ & $p$ & $p$ \\
\hline Right above knee & 0.129 & 0.496 & 0.754 & 0.299 & 0.786 & $0.854(0.274 ; 2.666)$ & 0.898 & 0.213 & 0.637 & 0.486 & 0.165 & 0.473 \\
\hline Right below knee & 0.011 & 0.975 & 0.813 & 0.389 & 0.040 & $0.255(0.069 ; 0.942)$ & 0.368 & 0.233 & 0.893 & 0.416 & 0.073 & 0.774 \\
\hline Left below knee & 0.086 & 0.771 & 0.237 & 0.335 & 0.050 & $0.270(0.073 ; 1.000)$ & 0.237 & 0.968 & 0.065 & 0.168 & 0.732 & 0.571 \\
\hline Right leg sum & 0.050 & 0.224 & 0.510 & 0.261 & 0.956 & $0.968(0.304 ; 3.080)$ & 0.988 & 0.580 & 0.292 & 0.447 & 0.053 & 0.546 \\
\hline Left leg sum & 0.112 & 0.942 & 0.618 & 0.977 & 0.502 & $1.540(0.437 ; 5.431)$ & 0.697 & 0.463 & 0.655 & 0.337 & 0.288 & 0.728 \\
\hline
\end{tabular}




\section{Discussion}

This is the first prospective multicenter study evaluating LLL incidence in cervical cancer patients after a uterine procedure with SLN biopsy, without systematic PLND. The group of 150 patients was prospectively evaluated using both objective and subjective LLL assessments.

The study revealed that LLL develops even after the SLN biopsy only; cumulative incidence at 24 -months post-surgery reached $17.3 \%$ for mild and $9.2 \%$ for moderate LLL, while severe LLL developed in one patient only $(0.7 \%)$. The median LLL onset time in the whole cohort was nine months. The risk of LLL development was not impacted by other factors such as the number of removed SLNs, surgical approach, adjuvant radiotherapy, type of uterine procedure, age, or BMI. Only $10.7 \%$ of patients subjectively reported LLL, and we found a weak correlation between objectively assessed and patient-reported LLL only for the right leg in moderate and mild + moderate subgroups. The important finding of our study was the high rate of transient edema, observed in $22 \%$ of the patients and characterized as a single episode of swelling that resolved without intervention until the next follow-up visit.

The incidence of LLL after standard surgical treatment, including PLND, of cervical cancer varies broadly in the literature, in the range of $3-62 \%[7-15,25,26,31]$. Such great variation is likely attributed to the flaws in LLL assessment, such as the absence of objective assessment methods, the simple postoperative assessment instead of longitudinal repeated follow-up, as well as a short period between the surgery and endpoint assessment. Moreover, out of more than 30 studies published since 2010 that report LLL incidence in cervical cancer survivors, the majority are based on retrospective cohorts in which the methodology of LLL evaluation is described vaguely or is completely missing [8,26,31,38-42].

Out of ten identified prospective studies, the description of LLL assessment methodology is only vaguely portrayed in two [43,44]; three studies were based on subjective reports [45-47]; and only two were based on objective diagnostic methods (bioimpedance spectroscopy, CT, or MRI) $[25,48]$. The last three prospective studies utilized objective assessment using circumferential measurements [7,10,19]. In the first study, $34.8 \%(48 / 138)$ of patients developed LLL during the two years of follow-up [10]. In this study, however, any exceedance of the $>10 \%$ threshold at any of seven follow-up visits was considered LLL, which undoubtedly led to an overestimation of the results because transient edema cases were not excluded. In the second study of only 39 patients, the prevalence of LLL was similar (35.9\%). The biggest weakness of this study, apart from the limited cohort, is the short follow-up of only six months, which could again lead to LLL prevalence overestimation since the swelling of the limbs in the first year post-surgery is very likely to be transient [49]. In the last study, LLL one-year post-surgery was identified in $34.5 \%$ of patients $(20 / 58)$. However, in this study, a low threshold of $>2 \%$ LVI was adopted in the more affected limb accompanied by other LLL symptoms [7].

Data on the risk of LLL in cervical cancer patients after SLN biopsy without simultaneous PLND are still scarce, yet they all conclude on a positive impact of decreased radicality of lymph node staging on the risk of LLL $[25,26,31,50]$. Again, however, all previously published studies have serious methodological limitations.

In a retrospective Japanese study, none out of 70 patients after SLN biopsy developed LLL as compared to $13.4 \%$ of 97 patients after systematic PLND [26]. A similar outcome was reported in another retrospective cohort, reporting zero (0/139) occurrence versus $22.4 \%$ $(15 / 67)$ of LLL patients after SLN biopsy and PLND, respectively [31]. In the first paper, the LLL assessment methodology description is limited to the statement that lymphatic complications were assessed using International Society Lymphology Guidelines [2]. In the second study, the method used for LLL detection is completely missing.

The risk of LLL development after SLN biopsy was also studied in two prospective studies. In the first cohort of 35 patients, new symptomatic LLL (stage II and above) was identified at 42 months in two of the $23(8.7 \%)$ cervical cancer patients after SLN biopsy, but in five of 12 patients (42\%) after PLND [25]. However, the groups were not well balanced 
in terms of risk factors, and the PLND group received adjuvant treatment significantly more often [25]. The second study, SENTICOL II, comparing outcomes of 101 patients after PLND and 106 patients after SLN biopsy, concluded that LLL symptoms reported by patients were significantly less severe after SLN biopsy. This outcome was based on the evaluation of a quality-of-life questionnaire, while the differences in objectively measured thigh circumferences were not significant [50]. Nevertheless, the objective assessment of LLL was based on only two circumferential measurements of the thigh, not allowing for limb volume calculation. Assessments were performed only in a limited period of 6 months after the surgery, and, finally, preoperative measurements were compared to a maximal value acquired at any of the three measurements performed early after surgery (at 1, 3, 6 months), therefore not excluding the patients with transient edema [50].

A substantially favorable impact of SLN biopsy on LLL risk was also reported for other pelvic gynecologic cancers [51]. A prospective study of 188 endometrial cancer patients revealed that replacement of PLND by SLN biopsy decreased LLL incidence up to 14-fold [28]. However, the compared cohorts were not equal in prognostic factors, which, among other things, caused more frequent administration of adjuvant radiotherapy in the PLND group (58.7\% vs 13.9\%) [28]. In another large cohort of 2535 vulvar cancer patients, a five-fold lower risk of LLL was observed in the SLN group compared to patients after inguinofemoral lymph node dissection [27]. In this meta-analysis, studies with a wide variety of objective diagnostic and rating criteria were combined; hence, at least some bias in the comparisons is expected [27].

Overall, preliminary data from retrospective and small prospective cohorts in gynecological cancer raised expectations for the elimination of the risk of LLL after SLN biopsy. This anticipation was, unfortunately, not confirmed by our study. Although a severe form of persistent LLL was almost not present (a single case, $0.7 \%$ ), a mild or moderate form occurred in a total of $26.5 \%$ of cases. Nevertheless, we are not the first study reporting a substantial risk of LLL after SLN biopsy in the pelvis. A similar incidence (25\% vs. $24 \%$ ) of LLL was observed in a prospective study on 97 endometrial cancer patients after both techniques of lymph node staging (i.e., SLN biopsy and PLND) [52].

Our study also revealed that patient-reported and objective LLL have to be clearly distinguished. Cumulative incidence at 24 months was $27.2 \%$ for objective LLL while it was $10.7 \%$ for self-reported LLL, showing only a weak and partial correlation (observed only for right leg) between those two types of assessment modalities. Only $50 \%$ of patients self-reporting LLL had LLL confirmed objectively. Out of patients with moderate/severe LLL and mild LLL, only $21.7 \%$ and $19.0 \%$ subjectively reported edema.

The relationship between objective limb volume changes and subjective symptoms was previously studied in a prospective study of 136 cervical cancer patients utilizing the Gynecologic Cancer Lymphedema Questionnaire (GCLQ), which consists of numerous LLL-related symptoms [53,54]. As much as $48 \%$ of all patients had a GCLQ score increment $\geq 4$ points during a postoperative assessment, but less than half of them had LVI 10\%. On the other hand, $60 \%$ of LVI $>10 \%$ of patients reported LLL on the GCLQ. The prospective EMBRACE study of locally advanced cervical cancer reported that prevalence of LLL at five years after the end of treatment was 15\% when assessed by a physician and $34 \%$ using patient-reported symptoms (EORTC QLQ-CX24) [55]. Four percent of patients were not diagnosed with LLL; however, they reported quite a bit/very much swelling of the limb. At the same time, $57.7 \%$ of mild LLL and $22.4 \%$ of moderate LLL patients reported no/only a little limb swelling [55]. Other studies assessing both objective ad subjective LLL in cervical cancer survivors do not allow for correlation analyses between them, not providing the information about the number of patients with either or both positive assessments $[48,56]$.

Numerous risk factors related to LLL were previously described in the literature, such as adjuvant radiotherapy [10,57], the extent of PLND with the emphasis on the number of removed LN [9,15,20-23], removal of circumflex iliac nodes [9,16,41], FIGO stage [23], and increasing BMI [12,57]. In our study, none of the tested factors was proven significant. The only exception was the surgical approach, where laparotomy was inversely related to 
below-knee edema. This was, however, only marginally significant and lacks justification why should minimally invasive surgery be a risk factor for LLL development. The lack of association between radiation therapy and LLL development was likely due to the low rate of adjuvant treatment administration in the whole study cohort (only $12 \%$ of patients). Most importantly, the number of removed SLNs on a respective side did not correlate with LLL development in the limb. Therefore, we can conclude that number of removed SLNs ( 1.5 per side on average; 3 per patient) is already below the risk number threshold, which was previously described in the literature to be between 10 to $31[9,15,20-23]$.

Our study represents the biggest reported prospective cohort of cervical cancer patients treated by uterine surgery with SLN biopsy only, who were prospectively evaluated by standardized objective and subjective LLL assessment methods. In order to overcome the previously mentioned limitations in the methodology, we employed a highly sensitive LLL assessment method based on serial circumferential measurements of the limbs, measured in six-month periods over the course of 24 months. The used threshold of $10 \% \mathrm{LVI}$ is based on a prior correlation of volume thresholds with patient-reported outcomes, which showed that an increase of $>7 \%$ in the circumferential sums provides a clinically meaningful definition of LLL (converted, $>7 \%$ circumferential increase approximately corresponds to LVI of $>10-12 \%$ ) [35]. Frequent, repeated assessments also allowed us to distinguish LLL from transient edema from other causes. Another important advantage is a precise standardization of this objective assessment method. Circumferential measurements in other studies were done in $10 \mathrm{~cm}$ intervals, usually starting from the medial ankle, and therefore not measuring comparable anatomical regions across patients with different leg lengths. We adopted this technique and measured circumferences at five anatomically standardized levels based on bony landmarks, allowing for unbiased inter- and intraindividual comparisons based on the comparable anatomical sections.

Amongst limitations, due to the multicenter design, circumference measurements were taken by dozens of investigators, which, despite detailed instructions, can lead to inaccuracies in individual measurements. The questionnaire used for the assessment of subjective patient-reported LLL was not standardized, and patients reported only the presence of swelling at different levels corresponding to sections used for objective measurement. Finally, due to the observational character, our study does not allow for comparison with the control group of patients after systematic pelvic lymphadenectomy. Therefore, the results can only be compared with previously published data, which are mainly retrospective and varying in diagnostic and assessment methods, meaning that direct comparison of the results is imprecise.

\section{Conclusions}

In conclusion, our study showed that PLND replacement by SLN biopsy in the surgical treatment of cervical cancer does not eliminate the risk of LLL development. Cumulative incidence of mild and moderate LLL at 24 months reached $17.3 \%$ and $9.2 \%$, respectively, with a median onset time of nine months after surgery.

The high rate of transient edema and the weak correspondence of patient-reported symptoms with the objective findings emphasize that a reliable LLL assessment requires a standardized methodology based on objective and repeated measurements.

Supplementary Materials: The following are available online at https:/ / www.mdpi.com/article/ 10.3390/cancers13102360/s1, Figure S1: Secondary lymphedema assessment schema, Figure S2: Individual fluctuations of limb volume change in patients with objective LLL, Figure S3: Distribution of the $10-19 \%$ and $>20 \%$ volume increase of right and left leg divided into above- and below-knee segments, Figure S4: Incidence of transient edema, Table S1: Objective LLL onset stratified by the laterality and overview of predisposing risk factors, Table S2: Risk factors analysis associated with objective LLL at 24 months follow up-full data. 
Author Contributions: Conceptualization: D.C. and R.K.; methodology: all authors; data analysis and statistics: J.J., M.B.; investigation of patients: D.C., S.M., J.K., R.P., A.T., I.Z., A.P., L.L., B.S., J.P. (Jordi Ponce), M.F., O.A.-S., P.K., K.Z., J.P. (Jiri Presl), A.P.-M., S.T., I.V., M.R., F.F., C.K. and R.K.; original draft preparation: D.C., M.B.; review and editing: all authors. All authors have read and agreed to the published version of the manuscript.

Funding: This work was supported by Charles University in Prague (UNCE 204065 and PROGRES Q28/LF1) and by a grant from the Czech Health Research Council (NV19-03-00023). The funders had no role in the design of the study; in the collection, analyses, or interpretation of data; in the writing of the manuscript, or in the decision to publish the results.

Institutional Review Board Statement: The study was conducted according to the guidelines of the Declaration of Helsinki, and approved by the Institutional Review Board of the leading institution (General University Hospital in Prague, Czech Republic) in 06/2015 under the registration number $105 / 15$.

Informed Consent Statement: Informed consent was obtained from all subjects involved in the study.

Data Availability Statement: The data sets used and/or analyzed during the current study are available from the corresponding author on reasonable request.

Acknowledgments: We would like to acknowledge the investigators from all 47 sites participating in the SENTIX trial (Adamik Zdenek, Department of Obstetrics and Gynecology, KNTB a.s Zlin, Czech Republic; Cadron Isabelle, AZ Turnhout, Turnhout, Belgium; Cornez Nathalie, CHU Ambroise Pare, Mons, Belgium; Coronado Martin Pluvio Jesus, Hospital Clinico San Carlos, Madrid, Spain; de Santiago García Francisco Javier, MD Anderson Cancer Center, Madrid, Spain; Dostalek Lukas, Gynecologic Oncology Center, Department of Obstetrics and Gynecology, First Faculty of Medicine, Charles University and General University Hospital, Prague, Czech Republic; Dundr Pavel, Institute of Pathology, First Faculty of Medicine, Charles University and General University Hospital, Prague, Czech Republic; Fastrez Maxime, CHU Saint Pierre, Brussels, Belgium; Germanová Anna, Gynecologic Oncology Center, Department of Obstetrics and Gynecology, First Faculty of Medicine, Charles University and General University Hospital, Prague, Czech Republic; Haidopoulos Dimitrios, Alexandra Hospital, Athens, Greece; Hryhorenki Andriy, Podilskyy Regional Oncological Centre, Vinnytsia, Ukraine; Kridelka Frederic, CHU de Liege, Notre Dame des Bruyeres, Belgium; Kipp Barbara, Lozerner Kantonsspital, Neue Frauenklinik, Switzerland; Landoni Fabio, Department of Obstetrics and Gynecology, Unit of Gynecologic Oncology Surgery, San Gerardo Hospital, Monza, Italy; Luc van Lonkhuijzen, Academic Medical Center Amsterdam, Netherlands; Luyckx Mathieu, Saint-Luc University Clinics, Brussels, Belgium; Petr Valha and Martin Michal, Hospital České Budějovice, Czech Republic; Maja Pakiž, University Medical Centre, Maribor, Slovenia; Francesco Raspagliesi, Gynecologic Oncology Department; Fondazione IRCCS Istituto Nazionale Tumori-Milan, Milan, Italy; Poka Robert, University of Debrecen, Department of Obstetrics and Gynecology, Debrecen, Hungary; Smrkolj Spela, University Medical Centre Ljubljana, Ljubljana, Slovenia; Snyman Leon C., Kalafong Provincial Tertiary Hospital, South Africa; Staringer Juan Carlos, Hospital Espanol de Buenos Aires, Caba, Argentina, and Hospital de Alta Complejidad de Formosa, Formosa, Argentina; Szatkowski Wiktor, M. Sklodowska-Curie Memorial Institute Krakow, Poland; Szewczyk Grzegorz, Institute of Mother and Child, Department of Gynecology and Obstetrics, Warsaw, Poland; Tamussino Karl, Medical University of Graz, Graz, Austria; Toth Robert, Oncology Institute of East Slovakia, Košice, Slovakia; Tummers Philippe, University Hospital Gent, Belgium; Dariusz Wydra, Department of Gynecology, Gynecologic Oncology and Gynecologic Endocrinology, University Clinical Center in Gdansk, Poland) and members of the Steering Committee (Dusek Ladislav, Institute of Biostatistics and Analyses, Masaryk University, Brno, Czech Republic; Kucukmetin Ali, Northern Gynaecological Oncology Centre, Queen Elizabeth Hospital, Gateshead, UK; Querleu Denis, Institut Bergonie, Bordeaux, France; van der Zee Ate, University Medical Center, Groningen, Netherlands). We also thank all the medical specialists, data and case managers, secretaries, study coordinators, and other people involved in the SENTIX trial.

Conflicts of Interest: The authors declare no conflict of interest. 


\section{References}

1. Beesley, V.; Janda, M.; Eakin, E.; Obermair, A.; Battistutta, D. Lymphedema after gynecological cancer treatment: Prevalence, correlates, and supportive care needs. Cancer 2007, 109, 2607-2614. [CrossRef] [PubMed]

2. Executive Committee. The Diagnosis and Treatment of Peripheral Lymphedema: 2016 Consensus Document of the International Society of Lymphology. Lymphology 2016, 49, 170-184.

3. Grada, A.A.; Phillips, T.J. Lymphedema: Pathophysiology and clinical manifestations. J. Am. Acad. Dermatol. 2017, 77, 1009-1020. [CrossRef] [PubMed]

4. Dunberger, G.; Lindquist, H.; Waldenstrom, A.C.; Nyberg, T.; Steineck, G.; Avall-Lundqvist, E. Lower limb lymphedema in gynecological cancer survivors-effect on daily life functioning. Support. Care Cancer 2013, 21, 3063-3070. [CrossRef] [PubMed]

5. Torre, L.A.; Islami, F.; Siegel, R.L.; Ward, E.M.; Jemal, A. Global Cancer in Women: Burden and Trends. Cancer Epidemiol. Biomark. Prev. 2017, 26, 444-457. [CrossRef]

6. Rob, L.; Skapa, P.; Robova, H. Fertility-sparing surgery in patients with cervical cancer. Lancet Oncol. 2011, 12, 192-200. [CrossRef]

7. Wang, X.; Ding, Y.; Cai, H.Y.; You, J.; Fan, F.Q.; Cai, Z.F.; An, P. Effectiveness of modified complex decongestive physiotherapy for preventing lower extremity lymphedema after radical surgery for cervical cancer: A randomized controlled trial. Int. J. Gynecol. Cancer 2020, 30, 757-763. [CrossRef]

8. Yoshihara, M.; Shimono, R.; Tsuru, S.; Kitamura, K.; Sakuda, H.; Oguchi, H.; Hirota, A. Risk factors for late-onset lower limb lymphedema after gynecological cancer treatment: A multi-institutional retrospective study. Eur. J. Surg. Oncol. 2020, 46, 1334-1338. [CrossRef]

9. Togami, S.; Kawamura, T.; Fukuda, M.; Yanazume, S.; Kamio, M.; Kobayashi, H. Risk factors for lymphatic complications following lymphadenectomy in patients with cervical cancer. Jpn. J. Clin. Oncol. 2018, 48, 1036-1040. [CrossRef] [PubMed]

10. Carlson, J.W.; Kauderer, J.; Hutson, A.; Carter, J.; Armer, J.; Lockwood, S.; Nolte, S.; Stewart, B.R.; Wenzel, L.; Walker, J.; et al. GOG 244-The lymphedema and gynecologic cancer (LEG) study: Incidence and risk factors in newly diagnosed patients. Gynecol. Oncol. 2020, 156, 467-474. [CrossRef]

11. Kim, S.I.; Lim, M.C.; Lee, J.S.; Kim, Y.J.; Seo, S.S.; Kang, S.; Yoo, C.W.; Nam, B.H.; Kim, J.Y.; Chung, S.H.; et al. Comparison of Lower Extremity Edema in Locally Advanced Cervical Cancer: Pretreatment Laparoscopic Surgical Staging with Tailored Radiotherapy Versus Primary Radiotherapy. Ann. Surg. Oncol. 2016, 23, 203-210. [CrossRef]

12. Kuroda, K.; Yamamoto, Y.; Yanagisawa, M.; Kawata, A.; Akiba, N.; Suzuki, K.; Naritaka, K. Risk factors and a prediction model for lower limb lymphedema following lymphadenectomy in gynecologic cancer: A hospital-based retrospective cohort study. BMC Women's Health 2017, 17, 50. [CrossRef]

13. Ohba, Y.; Todo, Y.; Kobayashi, N.; Kaneuchi, M.; Watari, H.; Takeda, M.; Sudo, S.; Kudo, M.; Kato, H.; Sakuragi, N. Risk factors for lower-limb lymphedema after surgery for cervical cancer. Int. J. Clin. Oncol. 2011, 16, 238-243. [CrossRef]

14. Biglia, N.; Librino, A.; Ottino, M.C.; Panuccio, E.; Daniele, A.; Chahin, A. Lower limb lymphedema and neurological complications after lymphadenectomy for gynecological cancer. Int. J. Gynecol. Cancer 2015, 25, 521-525. [CrossRef] [PubMed]

15. Mendivil, A.A.; Rettenmaier, M.A.; Abaid, L.N.; Brown, J.V., 3rd; Micha, J.P.; Lopez, K.L.; Goldstein, B.H. Lower-extremity lymphedema following management for endometrial and cervical cancer. Surg. Oncol. 2016, 25, 200-204. [CrossRef] [PubMed]

16. Hareyama, H.; Hada, K.; Goto, K.; Watanabe, S.; Hakoyama, M.; Oku, K.; Hayakashi, Y.; Hirayama, E.; Okuyama, K. Prevalence, classification, and risk factors for postoperative lower extremity lymphedema in women with gynecologic malignancies: A retrospective study. Int. J. Gynecol. Cancer 2015, 25, 751-757. [CrossRef]

17. Todo, Y.; Yamamoto, R.; Minobe, S.; Suzuki, Y.; Takeshi, U.; Nakatani, M.; Aoyagi, Y.; Ohba, Y.; Okamoto, K.; Kato, H. Risk factors for postoperative lower-extremity lymphedema in endometrial cancer survivors who had treatment including lymphadenectomy. Gynecol. Oncol. 2010, 119, 60-64. [CrossRef]

18. Roman, M.M.; Barbieux, R.; Nogaret, J.M.; Bourgeois, P. Use of lymphoscintigraphy to differentiate primary versus secondary lower extremity lymphedema after surgical lymphadenectomy: A retrospective analysis. World J. Surg. Oncol. 2018, 16, 75. [CrossRef] [PubMed]

19. Halaska, M.J.; Novackova, M.; Mala, I.; Pluta, M.; Chmel, R.; Stankusova, H.; Robova, H.; Rob, L. A prospective study of postoperative lymphedema after surgery for cervical cancer. Int. J. Gynecol. Cancer 2010, 20, 900-904. [CrossRef] [PubMed]

20. Abu-Rustum, N.R.; Alektiar, K.; Iasonos, A.; Lev, G.; Sonoda, Y.; Aghajanian, C.; Chi, D.S.; Barakat, R.R. The incidence of symptomatic lower-extremity lymphedema following treatment of uterine corpus malignancies: A 12-year experience at Memorial Sloan-Kettering Cancer Center. Gynecol. Oncol. 2006, 103, 714-718. [CrossRef]

21. Todo, Y.; Yamazaki, H.; Takeshita, S.; Ohba, Y.; Sudo, S.; Minobe, S.; Okamoto, K.; Kato, H. Close relationship between removal of circumflex iliac nodes to distal external iliac nodes and postoperative lower-extremity lymphedema in uterine corpus malignant tumors. Gynecol. Oncol. 2015, 139, 160-164. [CrossRef]

22. Fuller, J.; Guderian, D.; Kohler, C.; Schneider, A.; Wendt, T.G. Lymph edema of the lower extremities after lymphadenectomy and radiotherapy for cervical cancer. Strahlenther. Onkol. 2008, 184, 206-211. [CrossRef] [PubMed]

23. Kunitake, T.; Kakuma, T.; Ushijima, K. Risk factors for lower limb lymphedema in gynecologic cancer patients after initial treatment. Int. J. Clin. Oncol. 2020, 25, 963-971. [CrossRef]

24. Cibula, D.; Kocian, R.; Plaikner, A.; Jarkovsky, J.; Klat, J.; Zapardiel, I.; Pilka, R.; Torne, A.; Sehnal, B.; Ostojich, M.; et al. Sentinel lymph node mapping and intraoperative assessment in a prospective, international, multicentre, observational trial of patients with cervical cancer: The SENTIX trial. Eur. J. Cancer 2020, 137, 69-80. [CrossRef] [PubMed] 
25. Niikura, H.; Okamoto, S.; Otsuki, T.; Yoshinaga, K.; Utsunomiya, H.; Nagase, S.; Takano, T.; Ito, K.; Watanabe, M.; Yaegashi, N. Prospective study of sentinel lymph node biopsy without further pelvic lymphadenectomy in patients with sentinel lymph node-negative cervical cancer. Int. J. Gynecol. Cancer 2012, 22, 1244-1250. [CrossRef] [PubMed]

26. Togami, S.; Kubo, R.; Kawamura, T.; Yanazume, S.; Kamio, M.; Kobayashi, H. Comparison of lymphatic complications between sentinel node navigation surgery and pelvic lymphadenectomy in patients with cervical cancer. Jpn. J. Clin. Oncol. 2020, 50, 543-547. [CrossRef]

27. Huang, J.; Yu, N.; Wang, X.; Long, X. Incidence of lower limb lymphedema after vulvar cancer: A systematic review and meta-analysis. Medicine 2017, 96, e8722. [CrossRef]

28. Geppert, B.; Lonnerfors, C.; Bollino, M.; Persson, J. Sentinel lymph node biopsy in endometrial cancer-Feasibility, safety and lymphatic complications. Gynecol. Oncol. 2018, 148, 491-498. [CrossRef]

29. Accorsi, G.S.; Paiva, L.L.; Schmidt, R.; Vieira, M.; Reis, R.; Andrade, C. Sentinel Lymph Node Mapping vs Systematic Lymphadenectomy for Endometrial Cancer: Surgical Morbidity and Lymphatic Complications. J. Minim. Invasive Gynecol. 2020, 27, 938-945.e932. [CrossRef]

30. Biglia, N.; Zanfagnin, V.; Daniele, A.; Robba, E.; Bounous, V.E. Lower Body Lymphedema in Patients with Gynecologic Cancer. Anticancer Res. 2017, 37, 4005-4015. [CrossRef]

31. Yahata, H.; Kobayashi, H.; Sonoda, K.; Kodama, K.; Yagi, H.; Yasunaga, M.; Ohgami, T.; Onoyama, I.; Kaneki, E.; Okugawa, K.; et al. Prognostic outcome and complications of sentinel lymph node navigation surgery for early-stage cervical cancer. Int. J. Clin. Oncol. 2018, 23, 1167-1172. [CrossRef] [PubMed]

32. Pecorelli, S. Revised FIGO staging for carcinoma of the vulva, cervix, and endometrium. Int. J. Gynaecol. Obstet. 2009, 105, 103-104. [CrossRef] [PubMed]

33. Lymphoedema Framework. Best Practice for the Management of Lymphoedema; International Consensus; MEP Ltd.: London, UK, 2006; pp. 3-52.

34. Executive Committee of the International Society of Lymphology. The diagnosis and treatment of peripheral lymphedema: 2020 Consensus Document of the International Society of Lymphology. Lymphology 2020, 53, 3-19.

35. Spillane, A.J.; Saw, R.P.; Tucker, M.; Byth, K.; Thompson, J.F. Defining lower limb lymphedema after inguinal or ilio-inguinal dissection in patients with melanoma using classification and regression tree analysis. Ann. Surg. 2008, 248, 286-293. [CrossRef] [PubMed]

36. Vergote, I.; Pujade-Lauraine, E.; Pignata, S.; Kristensen, G.B.; Ledermann, J.; Casado, A.; Sehouli, J.; Mirza, M.; Fossati, R.; Marth, C.; et al. European Network of Gynaecological Oncological Trial Groups' requirements for trials between academic groups and pharmaceutical companies. Int. J. Gynecol. Cancer 2010, 20, 476-478. [CrossRef] [PubMed]

37. Dundr, P.; Cibula, D.; Nemejcova, K.; Ticha, I.; Bartu, M.; Jaksa, R. Pathologic Protocols for Sentinel Lymph Nodes Ultrastaging in Cervical Cancer. Arch. Pathol. Lab. Med. 2020, 144, 1011-1020. [CrossRef]

38. Yang, L.; Yuan, J.; Zeng, X.; Xi, M.; Wang, H. The outcomes and quality of life of young patients undergoing adjuvant radiotherapy versus non-radiotherapy following surgery treating early FIGO stage cervical squamous cell cancer in southwestern China. Sci. Rep. 2020, 10, 9583. [CrossRef]

39. Kashima, K.; Yahata, T.; Fujita, K.; Tanaka, K. Analysis of the complications after radical hysterectomy for stage IB, IIA and IIB uterine cervical cancer patients. J. Obstet. Gynaecol. Res. 2010, 36, 555-559. [CrossRef]

40. Wei, L.C.; Li, X.; Zhang, Y.; Dang, Y.Z.; Li, W.W.; Li, J.P.; Zhao, L.N.; Liu, S.J.; Li, X.; Shi, M. Individualized pelvic lymphadenectomy should follow neoadjuvant concurrent chemoradiotherapy for locally advanced cervical cancer. Medicine 2018, 97 , e0331. [CrossRef]

41. Yamazaki, H.; Todo, Y.; Takeshita, S.; Ohba, Y.; Sudo, S.; Minobe, S.; Okamoto, K.; Yamashiro, K.; Kato, H. Relationship between removal of circumflex iliac nodes distal to the external iliac nodes and postoperative lower-extremity lymphedema in uterine cervical cancer. Gynecol. Oncol. 2015, 139, 295-299. [CrossRef]

42. Hoogendam, J.P.; Verheijen, R.H.; Wegner, I.; Zweemer, R.P. Oncological outcome and long-term complications in robot-assisted radical surgery for early stage cervical cancer: An observational cohort study. BJOG Int. J. Obstet. Gynaecol. 2014, 121, 1538-1545. [CrossRef] [PubMed]

43. Wolf, B.; Ganzer, R.; Stolzenburg, J.U.; Hentschel, B.; Horn, L.C.; Hockel, M. Extended mesometrial resection (EMMR): Surgical approach to the treatment of locally advanced cervical cancer based on the theory of ontogenetic cancer fields. Gynecol. Oncol. 2017, 146, 292-298. [CrossRef]

44. Höckel, M.; Wolf, B.; Schmidt, K.; Mende, M.; Aktas, B.; Kimmig, R.; Dornhöfer, N.; Horn, L.-C. Surgical resection based on ontogenetic cancer field theory for cervical cancer: Mature results from a single-centre, prospective, observational, cohort study. Lancet Oncol. 2019, 20, 1316-1326. [CrossRef]

45. Wallin, E.; Falconer, H.; Radestad, A.F. Sexual, bladder, bowel and ovarian function 1 year after robot-assisted radical hysterectomy for early-stage cervical cancer. Acta Obstet. Et Gynecol. Scand. 2019, 98, 1404-1412. [CrossRef] [PubMed]

46. Pieterse, Q.D.; Kenter, G.G.; Maas, C.P.; de Kroon, C.D.; Creutzberg, C.L.; Trimbos, J.B.; Ter Kuile, M.M. Self-reported sexual, bowel and bladder function in cervical cancer patients following different treatment modalities: Longitudinal prospective cohort study. Int. J. Gynecol. Cancer 2013, 23, 1717-1725. [CrossRef]

47. Froding, L.P.; Ottosen, C.; Mosgaard, B.J.; Jensen, P.T. Quality of life, urogynecological morbidity, and lymphedema after radical vaginal trachelectomy for early-stage cervical cancer. Int. J. Gynecol. Cancer 2015, 25, 699-706. [CrossRef] [PubMed] 
48. Hayes, S.C.; Janda, M.; Ward, L.C.; Reul-Hirche, H.; Steele, M.L.; Carter, J.; Quinn, M.; Cornish, B.; Obermair, A. Lymphedema following gynecological cancer: Results from a prospective, longitudinal cohort study on prevalence, incidence and risk factors. Gynecol. Oncol. 2017, 146, 623-629. [CrossRef]

49. Kilbreath, S.L.; Lee, M.J.; Refshauge, K.M.; Beith, J.M.; Ward, L.C.; Simpson, J.M.; Black, D. Transient swelling versus lymphoedema in the first year following surgery for breast cancer. Support. Care Cancer 2013, 21, 2207-2215. [CrossRef]

50. Gianoni, M.; Mathevet, P.; Uzan, C.; Bats, A.S.; Magaud, L.; Boutitie, F.; Lecuru, F. Does the Sentinel Lymph Node Sampling Alone Improve Quality of Life in Early Cervical Cancer Management? Front. Surg. 2020, 7, 31. [CrossRef]

51. Dessources, K.; Aviki, E.; Leitao, M.M., Jr. Lower extremity lymphedema in patients with gynecologic malignancies. Int. J. Gynecol. Cancer 2020, 30, 252-260. [CrossRef]

52. Watson, C.H.; Lopez-Acevedo, M.; Broadwater, G.; Kim, A.H.; Ehrisman, J.; Davidson, B.A.; Lee, P.S.; Valea, F.; Berchuck, A.; Havrilesky, L.J. A pilot study of lower extremity lymphedema, lower extremity function, and quality of life in women after minimally invasive endometrial cancer staging surgery. Gynecol. Oncol. 2019, 153, 399-404. [CrossRef] [PubMed]

53. Carter, J.; Huang, H.Q.; Armer, J.; Carlson, J.W.; Lockwood, S.; Nolte, S.; Stewart, B.R.; Kauderer, J.; Hutson, A.; Walker, J.L.; et al. GOG 244-The LymphEdema and Gynecologic cancer (LEG) study: The association between the gynecologic cancer lymphedema questionnaire (GCLQ) and lymphedema of the lower extremity (LLE). Gynecol. Oncol. 2019, 155, 452-460. [CrossRef] [PubMed]

54. Carter, J.; Raviv, L.; Appollo, K.; Baser, R.E.; Iasonos, A.; Barakat, R.R. A pilot study using the Gynecologic Cancer Lymphedema Questionnaire (GCLQ) as a clinical care tool to identify lower extremity lymphedema in gynecologic cancer survivors. Gynecol. Oncol. 2010, 117, 317-323. [CrossRef] [PubMed]

55. Najjari Jamal, D.; Pötter, R.; Haie-Meder, C.; Lindegaard, J.C.; Juergenliemk-Schulz, I.M.; Mahantshetty, U.; Segedin, B.; Bruheim, K.; Hoskin, P.; Rai, B.; et al. Physician assessed and patient reported lower limb edema after definitive radio(chemo)therapy and image-guided adaptive brachytherapy for locally advanced cervical cancer: A report from the EMBRACE study. Radiother. Oncol. 2018, 127, 449-455. [CrossRef] [PubMed]

56. Malmsten, C.; Hellberg, P.; Bergmark, K.; Dahm-Kahler, P. Long-term fertility, oncological, and quality-of-life outcomes after trachelectomy in early stage cervical cancer. Arch. Gynecol. Obstet. 2019, 299, 1033-1041. [CrossRef]

57. Beesley, V.L.; Rowlands, I.J.; Hayes, S.C.; Janda, M.; O’Rourke, P.; Marquart, L.; Quinn, M.A.; Spurdle, A.B.; Obermair, A.; Brand, A.; et al. Incidence, Risk Factors, and Estimates of a Woman's Risk for Developing Secondary Lower Limb Lymphedema and Lymphedema-Specific Supportive Care Needs in Women Treated for Endometrial Cancer. Obs. Gynecol. Surv. 2015, 70, 176-177. [CrossRef] 